\title{
Pubertal Delay. The challenge of a timely differential diagnosis between Congenital Hypogonadotropic Hypogonadism (CHH) and Constitutional Delay of Growth and Puberty (CDGP): a narrative review.
}

Journal: Minerva Pediatrica

Paper code: Minerva Pediatr-5860

Submission date: April 2, 2020

Article type: Review Article

Files:

1. Manuscript

Version: 1

Description: Manuscript

File format: application/vnd.openxmlformats-officedocument.wordprocessingml.document

2. Figures 1

Version: 1

Description: Figure 1

File format: application/pdf 
Pubertal Delay. The challenge of a timely differential diagnosis between Congenital Hypogonadotropic Hypogonadism (CHH) and Constitutional Delay of Growth and Puberty (CDGP): a narrative review.

Arianna Bollino $^{1}$, Biagio Cangiano ${ }^{1,2}$, Giovanni Goggi ${ }^{1,2}$, Silvia Federici $^{1,2}$, Paolo Duminuco ${ }^{2}$, Luca Giovanelli $^{1,2}$, Elena Galazzi ${ }^{2}$, Valeria Vezzoli ${ }^{2}$, Luca Persani ${ }^{1,2}$, Marco Bonomi 1

${ }^{1}$ Department of Clinical Sciences and Community Health, University of Milan, Milan, Italy

${ }^{2}$ Department of Endocrine and Metabolic Diseases, IRCCS Istituto Auxologico Italiano, Milan, Italy

Keywords: idiopathic hypogonadotropic hypogonadism, GnRH deficiency, inhibin B, genetic, dynamic test

\section{Corresponding Authors:}

- Luca Persani, MD PhD

Dipartimento di Medicina Endocrino-Metabolica

IRCCS Istituto Auxologico italiano

P.le Brescia 20 - 20149 Milano

Mail: luca.persani@unimi.it

- Biagio Cangiano, MD

Dipartimento di Medicina Endocrino-Metabolica

IRCCS Istituto Auxologico Italiano

P.le Brescia 20 - 20149 Milano

Phone: +39-3343177491

Mail: $\underline{\text { b.cangiano@auxologico.it }}$ 
Distinguishing between Constitutional Delay of Growth and Puberty (CDGP) and Congenital Hypogonadotropic Hypogonadism (CHH) may be challenging. CDGP and $\mathrm{CHH}$ appear to belong to the same clinical spectrum (with low sex hormones and low LH and FSH), although one is classically transient and known as a self-limited form of delayed puberty (CDGP) while the other is permanent $(\mathrm{CHH})$. Thus, the clinical history and the outcomes of these two conditions require different approaches, and an adequate and timely management for the patients is mandatory. Since the initial presentation of CDGP and $\mathrm{CHH}$ is almost identical and given the similarities of CDGP and partial forms of $\mathrm{CHH}$ (i.e. patients with partial and early interrupted pubertal deyelopment) the scientific community has been struggling to find some diagnostic tests able to allow an accurate differential diagnosis between these two conditions in delayed puberty. In this reviewy provide an up to date insight on the tests available, their meanings and accuracy, as medi as some clues to effectively differentiate between constitutional pubertal delay and pathologic $\mathrm{CHH}$.
\end{abstract}




\section{Page 3 of 23}

\section{Delay of puberty}

\section{The process of puberty and its delay}

Puberty is the transition period between childhood and adulthood in which each different stage-is the result of the action of neuroendocrine factors that regulate the journey to sexual maturity through physical and hormonal changes. Pubertal development begins due to the spontaneous activation of the hypothalamus-pituitary-gonadal axis (HPG axis), which stimulates the gonads to produce sex steroids (testosterone in males, estrogen in females): this results in growth spurt and the appearance of secondary sexual characteristics, and the process culminates in the achieving of a complete sexual maturity. Physiological pubertal development encompasses a predictable and sequential series of stages, as illustrated by Tanner and Marshall ${ }^{1}$. Usuall between the age of 8 and 13 years old in females, and the age of 9 and 14 years old in males, an increase of nypothalamic GnRH secretory pulses (quiescent during childhood) starts the process of puberit, stimulating the pituitary to secrete FSH and LH which, in turn, stimulate directly the gonads First signs of the pubertal development are represented by the testicular enlargement (testicular Polume $>4 \mathrm{~mL}$ ) in male and the breast budding (thelarche) in female. The mechanisms involvedini the timing of puberty are complex and currently not fully understood: what is known is that the onset of puberty is a multifactorial process in which diet, environment, genetic factors and even ethnicity play an important role ${ }^{2}$.

Normally the HPG axis is active during fetal life, and for a short period of time after birth called "minipuberty". This is the only period of childhood in which FSH and LH levels are measurable. After this brief window of activation, the axis remains quiescent until the beginning of puberty ${ }^{3,4}$. The physical changes that characterize puberty include the development of secondary sex characteristics along with the achievement of adult height, the initiation of spermatogenesis in males and menstrual cycles in females; the testis enlargement in males (volume $>4 \mathrm{ml}$ ) and the appearance of breast buds in females, are the clinical signs marking the onset of puberty. On the contrary, the appearance of pubic and axillary hair, though usually simultaneous to these early events, is regulated 
by the adrenal androgens, and, thus, its isolated advent should not be interpreted as the beginning of puberty ${ }^{5,6}$.

Pubertal delay refers to the absence of the first signs of pubertal development beyond the normal expected age for the population (more than 2-2.5 standard deviation values above the mean of the reference population) or, when puberty has previously started, failure of proper progression. ${ }^{7}$. Since puberty is a delicate phase from the psychological point of view, it is understandabie that a delay may have an important impact on the child. In fact, subjects with delayed puberty find themaselves at great discomfort with their peers regarding both height and secondary sexal characteristics ${ }^{4,8}$

\section{Causes of Delayed Puberty}

Delay of puberty is a very common condition, and it includes a vast variety of causes. We can distinguish between the more frequent and transient form, represented by the constitutional delay of growth and puberty (CDGP) and the other rarer and usually permanent pathologic conditions, such as the primary and secondary hypogonadisms (Table 1).

Primary hypogonadism, also known as hypergonadgtropic hypogonadism, refers to a gonadal disfunction, where the central compartment of the HPG axis activates normally but the gonads do not respond as expected. This condition can be diagnosed and differentiated from the other forms of pubertal delays through the medical history, the physical examination and particularly through both the hormone leveis. Characterized by low sex steroids and high gonadotropin levels and diagnostic imaging.

Secondary/central or hypogonadotropic hypogonadism includes hormonal disorders that may be due to either an organic (both structural and congenital defects) or functional (such as chronic illnesses or anorexia requiring nutritional rehabilitation) disease affecting either the pituitary and/or the hypothalamus. The most important organic form of secondary hypogonadism is represented by the Congenital Hypogonadotropic Hypogonadism (CHH), which can be either normosmic (nCHH) or associated with an olfactory defects in the so called Kallmann's Syndrome (KS) ${ }^{9}$. Etiopathogenesis of both forms is so far largely unknown, although a genetic background is strongly suggested. ${ }^{10}$ 
The CDGP refers to a benign, self-limited form of delayed puberty that usually represents an extreme of the normal spectrum of pubertal timing. It is the most common cause of pubertal delay, affecting $2-2.5 \%$ of the population and it is much more common in boys than girls ${ }^{7}$. The precise cause of CDGP is so far unknown. Nevertheless, the significant familial recurrence of this defect, which spans from 50 to $75 \%$, is indicative of a strong genetic component. Although the inheritance of the CDGP is variable, an autosomal dominant pattern, in association with environmental modifiers, has been frequently observed, either with a complete or incomplete penetrance. So far, no specific causal gene has been identified to account for the majority of cases of CDGP. Patients with CDGP may experience slower growth rate, which results in a lower final adult height ${ }^{5,12}$, delayed sexual maturation and delayed skeletal age compared to peers. Usually, it is a condition associated with good prognosis and normal achievement of full puberty, with. no effect on pabertal maturity.

Up to date, CDGP is a diagnosis of exclusion: pathelogic sanges of delay of puberty such as hypergonadotropic hypogonadism and either functional or oganic hypogonadotropic hypogonadism must be excluded before considering a diagnosis a CDGP. However, the differential diagnosis between CDGP and $\mathrm{CHH}$ can be extremely chaldenging since related to distinguish at an early age which children need to be treated from those who will undergo through normal puberty spontaneously. Leaving the diagnosis for later in life, though easier, may have negative consequences on the final height, self-esteem and reproductive system of the subjects ${ }^{13-17}$.

\section{CHH vs CDGP}

It is very hard to diagnose CDGP during initial evaluations. Both boys with $\mathrm{CHH}$ and boys with CDGP have the same clinical features, and most importantly they both have similar hormone level such as low levels of gonadotropins (FSH, LH) and sex steroids (testosterone in male and estradiol in female). Once ruled out systemic pathologies determining functional $\mathrm{HH}$, the differential diagnosis between these two conditions is not straightforward. 
There have been studies on the effectiveness of Sertoli cell markers or GnRH and hCG stimulation tests, but none of them has proven to be truly reliable ${ }^{18-20}$. If clinical features are a fundamental tool to identify subjects with high risk of $\mathrm{CHH}$, a correct knowledge of the meaning and accuracy of the diagnostic tests available could improve the clinician effectiveness in an early diagnosis (or at least a suspicion) and a timely intervention.

\section{Clinical features}

Primarily, in order to diagnose a pubertal delay, an accurate medieal history collection and a thorough physical examination are necessary. In males the testicular volume (which should be higher than $4 \mathrm{~mL}$ by the age of 14) should be measured using Prader's orchidometer ${ }^{9,21,22}$. Recently, some "cues" have been labeled as "red flags", indicating that the finding of these features might suggest a specific diagnosis or a diagnostic subgrøup (CDAP, Functional Hypogonadotropic Hypogonadism -FHH-, CHH, Hypergonadotropic Hypogonadism) ${ }^{7}$. The abnormal sense of smell, for example, is knowingly linked to CHH in the abovemientioned KS. Other hallmarks and symptoms of $\mathrm{CHH}$ that should be looked for include clefting of the palate and lips, hearing loss, alteration of digital bones, daltonism, nystagnias and 31 -nanual synkinesia ${ }^{23-26}$. Renal malformations are often seen in KS, so arenal bitrasound should be included to rule out renal disgenesis or agenesis.

Family history appears to be positive in both CDGP and CHH even with an overlap between the two conditions within the same family, so it cannot be considered a red flag (on the contrary, it makes the differential diagnosis even harder) ${ }^{27,28}$. Nevertheless, it is surely important to investigate concerning a familial recurrence for self-limited pubertal delays or $\mathrm{CHH} / \mathrm{KS}$, as well as other possible familial reports of either singular $\mathrm{CHH}-\mathrm{KS}$-related feature (i.e. anosmia, renal malformations, hearing loss, daltonism, etc..).

The presence of neonatal cryptorchidism (particularly the bilateral forms) and micropenis in male is an important finding to report in these patients. In fact, it can be explained by pre- and post-natal gonadotropin deficiency, and it is independent of olfactory disorders. Micropenis and cryptorchidism 
might lead to an early diagnosis of $\mathrm{CHH}$ because they are neonatal features strongly suggesting a lack of minipuberty ${ }^{6,29}$. Evaluation of the specific hormonal tests (LH, FSH and sex steroids) performed in the first three-six months of life might eventually confirm the lack of minipuberty. On the other hand, after this specific neonatal temporal window, there are no more indication in performing any hormonal tests, due to the physiological reductions of gonadotropins: therefore, after the first 6 months $\mathrm{CHH}$ can only be suspected on the basis of micropenis and cryptorchidism, but it stitl needs to be confirmed ${ }^{4,29,30}$. Unfortunately, in the neonatal period, no specific signs might be searched for in $\mathrm{CHH}$ female patients, since they do not differentiate from the healthy subjects. Patients with $\mathrm{CHH}$ have normal stature growth during childhood, and the absence of long-bone epiphyseal closure explains these patients' frequent eunuchoid aspect and relative tallness; also, retarded bone maturation, osteopenia and osteoporosis are often found in these patientswen the diagnosis is made later in life ${ }^{31-34}$.

Other important findings in physical examination includedrow height, low BMI and low growth velocity which could point out functional forms of $\mathrm{H}^{2} \mathrm{y}^{22}$.

In the absence of these findings, and especially if there is a family history of constitutional delay of puberty, the most probable diagnosis is CPQP which would not necessitate further analyses ${ }^{7}$.

However, the abovementioned congenital abnormalities are often not evident during childhood and the clinical features of GnRH deficiency become evident only at the time of puberty. Therefore it is much more common to reach a diagnosis during adolescence because of the signs and symptoms connected to the lack of puberty, such as eunuchoid body proportions (upper/lower body ratio less than 1 with an arm span $6 \mathrm{~cm}$ greater than standing height, reflecting the delayed closure of the epiphysis of long bones in the absence of gonadal steroids), high-pitched voice and prepubertal testes in the male: all these features are the consequences of the failure to establish a timely diagnosis of hypogonadism ${ }^{35}$. During adolescence, patients with complete or partial CHH forms seek medical help for absent or minimal virilization, whereas in the adult onset forms patients usually complain 
about low libido and erectile disfunction. In most of $\mathrm{CHH}$ patients, puberty never actually occurs, which is the reason for the lack of secondary sexual characteristics that we listed here above, but the same clinical features are initially found in CDGP patients. Nonetheless, in patients with isolated GnRH deficiency the finding of a partial progression through puberty followed by a permanent arrest of sexual maturation is not uncommon, which makes the differentiation between the two conditions even harder ${ }^{36}$. The association between $\mathrm{CHH}$ and a decreased or absent sense of smell (hryposmia and anosmia respectively) typical of the $\mathrm{KS}$ is the consequence of the common origin of olfactory and GnRH neurons ${ }^{37}$. This condition should be evaluated with a quantitative olfactory test; however, it should be noted that defects of smell only affect less than a haif of subjects with $\mathrm{CHH}$. Still, whenever present, olfactory defects should be considered a reliable clue towards the diagnosis of KS 38.

\section{Hormones and stimulation tests}

An important feature in $\mathrm{CHH}$ patients is the yery low cirelating gonadotropin levels, but this feature alone cannot be used to differentiate between Gigs and $\mathrm{CHH}$ in early adolescence, when gonadotropin levels are noimally low even in healthy subjects.

\section{Nocturnal sampling}

The study of LA nocturnal pulses has been proposed in this setting: in fact, the lack of nocturnal LH pulses in adolescence was described to be specific for hypogonadotropic hypogonadism. In one study published in 2002, the $91 \%$ of the prepubertal children examined (age 4-8 years old) showed a distinct pulsatile LH and/or FSH secretion: this pulsatile secretion is similarly observed in older prepubertal patients and suggests the existence of a sleep-entrained rhythm of gonadotropin secretion during prepuberty as well as during established puberty: so it seemed plausible to suppose that an absence of this pulsatile secretion with undetectable levels of LH and FSH could lead the diagnosis towards an hypogonadotropic hypogonadism; but surprisingly, when using ultrasensitive assays with lower limits of detection, a similar pulsatile fluctuation was found in patients with Kallmann's syndrome as well ${ }^{39}$. The only difference between prepubertal children and hypogonadotropic patients seems to be 
the absence of entrainment to nocturnal sleep and the low incidence of synchronization between LH and FSH pulses, resulting in the possibility of distinguishing patients with Kallmann's syndrome from patients with constitutional delay of growth basing on the nocturnal pattern of gonadotropin secretion ${ }^{39,40}$. However, the analysis of the nocturnal patterns of gonadotropins is a kind of evaluation which is definitely too much invasive and could hardly be used as a practical routine diagnostic test. This resulted in a shift of attention towards less invasive and less laborious tests.

In order to avoid the nocturnal sampling, the diagnostic utility of a single basal gonadotropin level has been looked at: some studies, in fact, showed that there are significantly lower basal gonadotropins in $\mathrm{CHH}$ patients than age- and Tanner stage-matched patients with CDGP (especially in females) ${ }^{41-43}$. It has indeed been demonstrated that $\mathrm{LH}$ and FSH levels over $0.2 \mathrm{U} / \mathrm{L}$ indicate successful onset of puberty. However, if the finding of gonadotropins tevers above $0.2 \mathrm{U} / \mathrm{L}$ points out patients with no sign of puberty that are about to start physical deviopment (thus not requiring further investigation but a simple "wait and see"strategy), it cannof be used to distinguish between partial CHH and CDGP in patients already having signs of puberty, that could have had a pubertal arrest. Similarly, if gonadotropins levels are below $0.2+1 / \mathrm{L}$ it is not possible to distinguish between an early stage CDGP and complete CHYH 7,44 .

\section{GnRH and GnRHa tests}

Several studies have been reported with the aim to demonstrate whether the LH or FSH levels response to provocative tests could accurately discriminate between the two conditions. Some of them, initially stated that it would be possible to diagnose $\mathrm{CHH}$ with $100 \%$ sensitivity and $96 \%$ specificity by assessing LH response to GnRH. However, these studies were conducted on small sized pools of very selected patients not reflecting the complexity and heterogeneity of the possible presentations of the disease ${ }^{45}$. The real effectiveness of GnRH-stimulated LH and FSH pulses in distinguishing CDGP from $\mathrm{CHH}$, in fact, is far less accurate. Indeed, it was shown that even if adolescents with CHH have overall lower stimulated LH levels compared with subjects with CDGP, up to $30 \%$ of these latter have LH responses indistinguishable from those with CDGP. So, once again, 
the main problem remains the overlap between the two conditions ${ }^{46}$. The use of GnRH agonists seemed to have a higher discriminatory potential compared to $\mathrm{GnRH}$ for dynamic testing in distinguishing CDGP from $\mathrm{CHH}^{47}$. The GnRH agonists studied include Nafarelin, Triptorelin, Buserelin and Leuprolide: they all have shown increased potency and half-life due to a greater affinity for the GnRH receptor, resulting in a much more effective stimulus for the activation of the gonadotropic cells in patients with CDGP. In a pilot study the authors found that the response to a single test dose of Nafarelin distinguished $\mathrm{CHH}$ from CDGP in a way similar to the sampling of nocturnal LH level ${ }^{48}$. However, all the studies had the same aborementioned limitations, with a retrospective design and a low number of selected $\mathrm{CHH}$ patients. On the contrary, GnRH test is widely used to identify an initial onset of puberty, in order to choose a wait and see strategy in patients without signs of puberty but a positive response to the test. In lact, beth GinRH test and GnRHa test point out if there is an activation of gonadotropic cells (which opeurs whenever puberty is started). However, since this activation has occurred alse in partial arms of $\mathrm{CHH}$ (forms in which puberty may not progress, but starts anyway), it is impossible to perform an accurate differential diagnosis. Thus, GnRH and GnRHa tests can both be used tor identify puberty onset rather than a true differential diagnosis between CDGP and CHH.

\section{Inhibin B, AMH, INSL3, $1 \mathrm{CG}$ and Kisspeptin dynamic testing}

Other endocrine tests that have been used to guide the differential diagnosis, including the measurement of the circulating markers of Sertoli cells (such as inhibin B), of immature Sertoli cells (such as AMH), and of Leydig cells (such as INSL3 and testosterone after hCG stimulation test).

INSL3 is a marker of Leydig cell function ${ }^{49}$ which has a low secretion during childhood while increasing during puberty and peaking in the adulthood ${ }^{50}$. It was reported that $\mathrm{CHH}$ male individuals have typically low INSL3 levels (either at diagnosis or during testosterone replacement therapy) that are prone to increase whether LH and/or hCG stimulated ${ }^{51}$. However, data so far available are insufficient to clearly identify the potential clinical utility of INSL3 measurements in differentiating CHH from CDGP. 
Inhibin B and AMH are both glycoproteins produced by Sertoli cells: their levels reach a peak after birth and then they decrease, but while inhibin B rises again with the onset of puberty as a result of the FSH stimulus, AMH keeps decreasing due to the down-regulation induced by the increasing Testosterone levels. Two recent studies evaluated Inhibin B measurement: one of them, including 82 subjects with delayed puberty, showed that circulating Inhibin B had a 93\% positive predictive value to identify patients with $\mathrm{CHH}$ from those with CDGP, while the measurement of AMH, T, FSH, LH were not as reliable markers for such differential diagnosis, even though their levels appeared to be lower in most of $\mathrm{CHH}$ patients compared to the CDGP patients 41 The lower reliability of AMH seemed to be linked to the fact that AMH responds to FSH thirough a non-classical pathway and it also normally decreases during puberty under the effect of Testosterone. In contrast, the second study found a lower positive predictive value of Inhibin B at distinguishigig CHH from CDGP, but the authors still concluded that, although it requires further verification, a single inhibin B level might be used as a first-line test in the diagnosis of $\mathrm{CHH}^{52}$. In fact, it was shown that the combined basal test (inhibin B plus LH) could be a valid alternative to GnRHa test, which is time consuming and more expensive, and some authors endorsed thisstrategy as a first line test of the patients with delayed puberty ${ }^{47}$.

The testing of AMH serum levels combined with inhibin B levels has proved to give comforting results in cases of glinical suspicion of puberty disorders, since these levels reflect Sertoli's cells health and number: while these tests can't discriminate with guaranteed accuracy between $\mathrm{CHH}$ and CDGP, however, they can be helpful in the early detection of testicular tubular damage ${ }^{41}$.

The use of HCG test in association with GnRH test and has also been suggested, combining shortterm HCG stimulation and long-term HCG stimulation followed by the classic GnRH stimulation test. Indeed, the peak testosterone response to the short-term and long-term HCG stimulation was found in one study to be significantly lower in CHH patients, as were the peak serum FSH responses to the GnRH stimulation ${ }^{53}$. Still also these data were never reproduced, and thus found no application in clinical practice. 
Finally, among the new frontiers of hormonal evaluation, also the responsiveness to the neuropeptide kisspeptin has been investigated in boys with delayed puberty: Chan YM et al. hypothesized in 2018 that kisspeptin would stimulate LH secretions in healthy subjects but not in CHH patients. Thus, a kisspeptin stimulation could stimulate overnight LH pulses in boys with emerging reproductive endocrine function, while the absence of response may be due to a true hypogonadotropic hypogonadism. The results showed different profiles of patients: the responders, the ones who were thought to have normal reproductive endocrine function, the non-responders (who were believed to have an underlying pathology concerning the pituitary), and ultinately a group of intermediate responders, that could be the cases diagnosed with partial HH. At this point, further studies are needed to see if the kisspeptin stimulation test in prepubertal children can accurately predict outcomes for boys presenting delayed puberty, since the study included 17 years oldpatients, and our main priority is to diagnose correctly the condition in pediatric patients, before derayed puberty shows itself ${ }^{54}$.

\section{Priming}

Another mean to investigate pubertal delay, which is also the treatment of choice in CDGP, is the socalled "priming" using low doses of sex homnones. In fact, recent studies have been focusing on the diagnostic utility of performing testosterone priming not only to treat CDGP, but to perform a differential diagnosis with $\mathrm{CHH}$, relying on the idea that after a three-months period of testosterone injections in boys with CDGP, the withdrawal of testosterone should awaken the hypothalamuspituitary axis, with an enlargement of the testis and an endogenous production of testosterone ${ }^{55}$. One of the advantages of this interventive approach is a shorter delay in the diagnosis, since the "diagnostic test" is also a treatment, with both psychological and physical benefits on height and virilization. Moreover more expensive test could be reserved to those who do not reach puberty even after testosterone priming ${ }^{55}$. On the other hand, it has to be considered that nowadays it is not known if, in $\mathrm{CHH}$ patients, a pretreatment with testosterone before a gonadotropin therapy could affect the future fertility potential of the subjects ${ }^{56-58}$. Concerning the side effects of testosterone priming 
(including acne and in a minority of cases also aggressive behavior and painful erections), it has to be said that they only occurred in boys who were treated with excessive doses of testosterone ${ }^{59}$. Anyway, although testosterone priming cannot be considered an "unsafe" treatment, patients and their family need to be informed of the connected risks, and most importantly, in case of priapism a urologist has to be consulted timely ${ }^{59}$.

The same approach has been attempted in female with a priming therapy using low doses of estradiol. The evidence that we have at the moment on females, however, is based mostly on $\beta$-Thalassemic patients, who are affected in 60-80\% of the cases by hypogonadotropic hypogonadism: In a 6-year prospective study concerning children (boys and girls) with absent or arrested puberty and $\beta$ Thalassemia, sex hormones priming proved to be successfur in inducing puberty in $80 \%$ of the subjects, suggesting that the estradiol priming could be as userul as the testosterone priming in the awakening of the hypothalamus-pituitary axis in the CDGP femairpatients ${ }^{60}$.

The data we analyzed also suggests that the priming techaigue could increase the discriminatory power of dynamic tests (such as GnRH stimulationgif performed before such tests, indicating an interesting application of the technique in tergis of the differential diagnosis between $\mathrm{CHH}$ and $\mathrm{CDGP}^{55}$

\section{Genetics}

The genetics underlying the two conditions is another aspect that needs to be carefully considered. Up to date, 60 genes are known to be associated with the multiple forms of hypogonadotropic hypogonadism ${ }^{10}$, all of them being genes that regulate development, migration and secretory function of GnRH neurons, but there is less knowledge regarding the genetic background of congenital delay of puberty. The family history that is found in the majority of the CDGP patients suggests that the genetic aspect of the condition is not to be underestimated. In fact, as already above mentioned, it seems that CDGP clusters in families ${ }^{61}$. In 2015 a study aimed in determining whether the genetic 
mutations linked to $\mathrm{CHH}$ could also be found in the boys with CDGP, showed that there is actually an overlap between the genetics of these two conditions, which could even share the same underlying pathophysiology ${ }^{62}$. These findings were confirmed in a further study that, despite being designed to find difference in the genetic architecture of the two conditions, found a similar genetic basis, even if a greater prevalence of $\mathrm{CHH}$ variants and oligogenicity were more typical of hypogonadal patients 63. So, the main utility of genetic studies, nowadays, remains the family counselling once the diagnosis is completed, rather than as a routine first-line test.

\section{Conclusions: what to do?}

Every careful reader should have understood by now that there are no strong and univocal evidences to guide us in the differential diagnosis and management of CDGP and $\mathrm{CHH}$. However, according to the pathophysiology of these two conditions, we can draw some gonsiderations which could lead us through this tangle of tests and approaches.

First of all, any treatment should be considered only when actually needed. Thus, before 14 years old 9,64,65 it is important to simply reassure patients gnd their parents since the most likely condition is normality. After 14 years gld, if no sign at all of puberty has intervened, the evaluation of gonadotropins could be highly useful to point out subjects that are about to start their (delayed) puberty, non-requiring other action than watchful follow up ${ }^{44}$. On the contrary, if gonadotropins are below $0.2 \mathrm{U}$, a GnRH test could be performed with the same purpose ${ }^{66}$.

Finally, in those not showing any of these signs of initial puberty, new markers such as inhibin B could be evaluated ${ }^{41}$, and, after a thorough discussion with the patient and their parents, a priming with low doses of sex hormones could be proposed, especially in patients suffering for their physical immaturity. Obviously no patient should ever be left untreated after 18 years old (this being by definition a $\mathrm{CHH}^{32,67}$ ), and after 16 years old a psychologic discomfort is very likely on the contrary of a CDGP thus demanding particular attention to a more interventional approach. 


\section{References}

1. Marshall WA, Tanner JM. Variations in the Pattern of Pubertal Changes in Boys. Arch Dis Child. 1970;45(13):13-23. http://adc.bmj.com/cgi/doi/10.1136/adc.44.235.291. Accessed October 21, 2019.

2. Sørensen K, Mouritsen A, Aksglaede L, Hagen CP, Mogensen SS, Juul A. Recent secular trends in pubertal timing: implications for evaluation and diagnosis of precocious puberty. Horm Res Paediatr. 2012;77(3):137-145. doi:10.1159/000336325.

3. Swee DS, Quinton R. Congenital Hypogonadotrophic Hypogonadism: Minipubertv and the Case for Neonatal Diagnosis. Front Endocrinol (Lausanne). 2019;10:97. doi:10.3389/fendo.2019.00097.

4. Swee DS, Quinton R. Congenital hypogonadotrophic hypogonadism : Nininipuberty and the case for neonatal diagnosis. Front Endocrinol (Lausanne). 2019;10(FEB). doi:10.3389/fendo.2019.00097.

5. Sedlmeyer IL, Palmert MR. Delayed Puberty: Analysis of a Large Case Series from an Academic Center. J Clin Endocrinol Metab. 2002;87(4):1613-1620. doi:10.1210/jcem.87.4.8395.

6. Varimo T, Miettinen PJ, Känsäkoski J, Raivio T, Hero M. Congenital hypogonadotropic hypogonadism, functional hypogonadotropisin or constizutional delay of growth and puberty? An analysis of a large patient series from a single tertiary center. Hum Reprod. 2017;32(1):147-153. doi:10.1093/humrep/dew294.

7. Abitbol L, Zborovski S, Palmert MR. Evaluation of delayed euberty: What diagnostic tests should be performed in the seemingly otherwise weis adolescent? Arch Dis Child. 2016;101(8):767-771. doi:10.1136/archdischild-2015-310375.

8. Harrington J, Palmert MR. Distinguishing constitutional delay of growth and puberty from isolated hypogonadotropic bypogonadism: Critical appraisal of available diagnostic tests. J Clin Endocrinol Metab. 2012;97(9):3056-3967. doi:10.1210/jc.2012-1598.

9. Palmert MR, Dunkel L. Delayed puberty. N Engl J Med. 2012;366(5):443-453. doi:10.1056/NEJMcp1109290.

10. Cangiano B, Swee DS, Quinton R, Bonomi M. Genetics of congenital hypogonadotropic hypogonadism:peculiarities and phenotype of an oligogenic disease. Hum Genet. 2020. doi:10.1007/s00439-020-02147-1.

11. Howard SR. The Genetic Basis of Delayed Puberty. Front Endocrinol (Lausanne). 2019:10:423. doi:10.3389/fendo.2019.00423.

12. Albanese A, Stanhope R. Predictive factors in the determination of final height in boys with constitutional delay of growth and puberty. J Pediatr. 1995;126(4):545-550. doi:10.1016/S0022-3476(95)70347-0.

13. Zachmann M. Therapeutic indications for delayed puberty and hypogonadism in adolescent boys. Horm Res Paediatr. 1991;36(3-4):141-146. doi:10.1159/000182148.

14. Zachmann M, Studer S, Prader A. Short-term testosterone treatment at bone age of 12 to 13 years does not reduce adult height in boys with constitutional delay of growth and adolescence. Helv Paediatr Acta. 1987;42(1):21-28.

15. Pozo J, Argente J. Ascertainment and treatment of delayed puberty. In: Hormone Research. Vol 60. ; 2003:35-48. doi:10.1159/000074498.

16. Soliman AT, Abdul Khadir MM, Asfour M. Testosterone treatment in adolescent boys with constitutional delay of growth and development. Metabolism. 1995;44(8):1013-1015. doi:10.1016/0026-0495(95)90098-5.

17. Richman RA, Kirsch LR. Testosterone treatment in adolescent boys with constitutional delay 
in growth and development. N Engl J Med. 1988;319(24):1563-1567. doi:10.1056/NEJM198812153192402.

18. Brown DC, Stirling HF, Butler GE, Kelnar CJ, Wu FC. Differentiation of normal male prepuberty and hypogonadotrophic hypogonadism using an ultrasensitive luteinizing hormone assay. Horm Res. 1996;46(2):83-87. doi:10.1159/000185001.

19. Kulin H, Demers L, Chinchilli V, Martel J, Stevens L. Usefulness of sequential urinary folliclestimulating hormone and luteinizing hormone measurements in the diagnosis of adolescent hypogonadotropism in males. J Clin Endocrinol Metab. 1994;78(5):1208-1211. doi:10.1210/jcem.78.5.8175980.

20. Dunkel L, Perheentupa J, Virtanen M, Mäenpää J. GnRH and HCG Tests Are Both Necessary in Differential Diagnosis of Male Delayed Puberty. Am J Dis Child. 1985;139(5).494-498. doi:10.1001/archpedi.1985.02140070068036.

21. Marshall WA, Tanner JM. Variations in the pattern of pubertal changes in boys. Arch Dis Child. 1970;45(239):13-23. doi:10.1136/adc.45.239.13.

22. Palmert MR, Dunkel L. Clinical practice. Delayed puberty. N Engl J Med. 2012;366(5):443453. doi:10.1056/NEJMcp1109290.

23. Bonomi M, Vezzoli V, Krausz C, et al. Characteristics of a nationwide cohort of patients presenting with isolated hypogonadotropic hypogonadism (JHH). Eur J Endocrinol. 2018;178(1):23-32. doi:10.1530/EJE-17-0065.

24. EVAIN-BRION D, GENDREL D, BOZZOLA M, CHAJSSSAIN JL, JOB IG. DIAGNOSIS OF KALLMANN'S SYNDROME IN EARLY INFANCY. Acta Pæediatría. 1982;71(6):937-940. doi:10.1111/j.1651-2227.1982.tb09552.x.

25. Grumbach MM. A window of opportunity the diagnosis of gonadotropin deficiency in the male infant. J Clin Endocrinol Metab. 2005;90(5):3122-3127. doi:10.1210/jc.2004-2465.

26. Bergadá I, Milani $C$, Bedecarrás $P$, et ail. Tiime course of the serum gonadotropin surge, inhibins, and anti-Müllerian hormone in normal newborn males during the first month of life. J Clin Endocrinol Metak. 2006,91(10).4092-4098. doi:10.1210/jc.2006-1079.

27. Howard SR, Guasti L, Ruiz-Babot G, et ar IGSF 10 mutations dysregulate gonadotropinreleasing hormone neuronal migration resulting in delayed puberty. EMBO Mol Med. 2016;8(6):62.6-542. doi:10.15252, emmm.201606250.

28. Zhu J, Choa REY Guo $M H$, et al. A shared genetic basis for self-limited delayed puberty and idiopathic hypogonadotropic hypogonadism. J Clin Endocrinol Metab. 2015;100(4):E646E654 doi:10.1210/jc.2015-1080.

29. Doty RL., Shaman P, Dann M. Development of the university of pennsylvania smell identification test: A standardized microencapsulated test of olfactory function. Physiol Behav. 1984;32(3):489-502. doi:10.1016/0031-9384(84)90269-5.

30. Quinton R, Mamoojee $\mathrm{Y}$, Jayasena CN, et al. Society for Endocrinology UK guidance on the evaluation of suspected disorders of sexual development: emphasizing the opportunity to predict adolescent pubertal failure through a neonatal diagnosis of absent minipuberty. Clin Endocrinol (Oxf). 2017;86(2):305-306. doi:10.1111/cen.13257.

31. Iolascon $\mathrm{G}$, Frizzi L, Bianco $\mathrm{M}$, et al. Bone involvement in males with Kallmann disease. Aging Clin Exp Res. 2015;27:31-36. doi:10.1007/s40520-015-0421-5.

32. Young J, Xu C, Papadakis GE, et al. Clinical Management of Congenital Hypogonadotropic Hypogonadism. Endocr Rev. 2019;40(2):669-710. doi:10.1210/er.2018-00116.

33. Uriarte MM, Baron J, Garcia HB, Barnes KM, Loriaux DL, Cutler GB. The effect of pubertal delay on adult height in men with isolated hypogonadotropic hypogonadism. J Clin Endocrinol Metab. 1992;74(2):436-440. doi:10.1210/jcem.74.2.1449545.

34. Behre HM, Kliesch S, Leifke E, Link TM, Nieschlag E. Long-Term Effect of Testosterone 
Therapy on Bone Mineral Density in Hypogonadal Men. J Clin Endocrinol Metab. 1997;82(8):2386-2390. doi:10.1210/jcem.82.8.4163.

35. Layman LC. Hypogonadotropic Hypogonadism. Endocrinol Metab Clin North Am. 2007;36(2):283-296. doi:10.1016/j.ecl.2007.03.010.

36. Nachtigall LB, Boepple PA, Pralong FP, Crowley WF. Adult-onset idiopathic hypogonadotropic hypogonadism - A treatable form of male infertility. $N$ Engl J Med. 1997;336(6):410-415. doi:10.1056/NEJM199702063360604.

37. Casoni F, Malone SA, Belle M, et al. Development of the neurons controlling fertility in humans: new insights from 3D imaging and transparent fetal brains. Development. 2016;143(21):3969-3981. doi:10.1242/dev.139444.

38. Lewkowitz-Shpuntoff HM, Hughes VA, Plummer L, et al. Olfactory phenotypic spectrum in idiopathic hypogonadotropic hypogonadism: pathophysiological and genetic implications. J Clin Endocrinol Metab. 2012;97(1):E136-44. doi:10.1210/jc.2011-2041.

39. Wu FC, Butler GE, Kelnar CJ, Stirling HF, Huhtaniemi I. Patterns of pulsatile luteinizing hormone and follicle-stimulating hormone secretion in prepubertal (midchildhood) boys and girls and patients with idiopathic hypogonadotropic hypogonadism (Kallmann's syndrome): a study using an ultrasensitive time-rescived immunofluorometric assay. $J$ Clin Endocrinol Metab. 1991;72(6):1229-1237. doi:10.1210/jcem-72-6-1229.

40. Sequera AM, Fideleff HL, Boquete HR, Pujol AB, Suárez MG, Ruibal gif. Basal ultrasensitive LH assay: A useful tool in the early diagnosis of male pubertal deray? J Pediatr Endocrinol Metab. 2002;15(5):589-596. doi:10.1515/1PEM 2002.15.5.589.

41. Coutant R, Biette-Demeneix E, Bouvattier C, et al. Baseline is hibin B and anti-Mullerian hormone measurements for diagnosis of hypogonadotropic hypogonadism $(\mathrm{HH})$ in boys with delayed puberty. J Clin Endocringl Meiab. 2010;95(12):5225-5232. doi:10.1210/jc.2010-1535.

42. Wilson DA, Hofman PL, Miles HL, Unwin KE, Nics srail CE, Cutfield WS. Evaluation of the buserelin stimulation test in diagrosing gonadotropin deficiency in males with delayed puberty. J Pediatr. 2006;148(1):89-94. do610.1016/j.jpeds.2005.08.045.

43. Sun QH, Zheng $\mathrm{Y}$, Zhang $X !$, Mu YMR. Role of gonadotropin-releasing hormone stimulation test in diagnosing gonadotropin deficiency in both males and females with delayed puberty. Chin Med JEngl\%. 2015;128(18):2439-2443. doi:10.4103/0366-6999.164926.

44. De Resende EAMIR., Lara BHJ, Reis JD, Ferreira BP, Pereira GA, Borges MF. Assessment of basal and gonalotropin-releasing hormone-stimulated gonadotropins by innunocherniluminometric and immunofluorometric assays in normal children. J Clin Endocrinol Metab. 2007;92(4):1424-1429. doi:10.1210/jc.2006-1569.

45. Zevenhuijzen $\mathrm{H}$, Kelnar $\mathrm{CJH}, \mathrm{Crofton} P \mathrm{PM}$. Diagnostic utility of a low-dose gonadotropinreleasing hormone test in the context of puberty disorders. Horm Res. 2004;62(4):168-176. doi:10.1159/000080324.

46. Marshall JC, Harsoulis P, Anderson DC, Mcneilly AS, Besser GM, Hall R. Isolated pituitary gonadotrophin deficiency: Gonadotrophin secretion after synthetic luteinizing hormone and follicle stimulating hormone-releasing hormone. Br Med J. 1972;4(5841):643-645. doi:10.1136/bmj.4.5841.643.

47. Binder G, Schweizer R, Blumenstock G, Braun R. Inhibin B plus LH vs GnRH agonist test for distinguishing constitutional delay of growth and puberty from isolated hypogonadotropic hypogonadism in boys. Clin Endocrinol (Oxf). 2015;82(1):100-105. doi:10.1111/cen.12613.

48. Ehrmann DA, Rosenfield RL, Cuttler L, Burstein S, Cara JF, Levitsky LL. A new test of combined pituitary-testicular function using the gonadotropin-releasing hormone agonist nafarelin in the differentiation of gonadotropin deficiency from delayed puberty: pilot 
studies. J Clin Endocrinol Metab. 1989;69(5):963-967. doi:10.1210/jcem-69-5-963.

49. Johansen ML, Anand-Ivell R, Mouritsen A, et al. Serum levels of INSL3, AMH, Inhibin B and Testosterone during pubertal transition in healthy boys. Reproduction. 2014;147(4):529535. doi:10.1530/REP-13-0435.

50. Trabado S, Maione L, Bry-Gauillard H, et al. Insulin-like peptide 3 (INSL3) in men with congenital hypogonadotropic hypogonadism/kallmann syndrome and effects of different modalities of hormonal treatment: A single-center study of 281 patients. J Clin Endocrinol Metab. 2014;99(2):E268-75. doi:10.1210/jc.2013-2288.

51. Trabado S, Maione L, Bry-Gauillard H, et al. Insulin-like peptide 3 (INSL3) in meen with congenital hypogonadotropic hypogonadism/Kallmann syndrome and effects of different modalities of hormonal treatment: a single-center study of 281 patients. $j$ Clin Endocrinol Metab. 2014;99(2):E268-75. doi:10.1210/jc.2013-2288.

52. Adan $L$, Lechevalier $P$, Couto-Silva $A C$, et al. Plasma inhibin $B$ and antimüllerian hormone concentrations in boys: Discriminating between congenital hyogonadotropic hypogonadism and constitutional pubertal delay. Med Sci Monit. 2010;16(11):511-517.

53. Segal TY, Mehta A, Anazodo A, Hindmarsh PC, Dattani MT. Role of Gonadotropin-Releasing hormone and human chorionic gonadotropin stimulation tests in differentiating patients with hypogonadotropic hypogonadism from those with constitutional delay of growth and puberty. J Clin Endocrinol Metab. 2009;94(3):780-785. doi:10.1210/jo:2008-0302.

54. Chan Y-M, Lippincott MF, Kusa TO, Seminara SB. Divergent resoonses to kisspeptin in children with delayed puberty. JCl insight. 2018;3/8). doi:10.11/2/jci.insight.99109.

55. Sukumar SP, Bhansali A, Sachdeva N et al. Diagnostic unite of testosterone priming prior to dynamic tests to differentiate constitutional delay in puberty from isolated hypogonadotropic hypogonadism. Clin Endocringf(0x). 2017;86(5):717-724. doi:10.1111/cen.13321.

56. Dwyer AA, Sykiotis GP, Hayes Fs, et al. Trial of Pee combinant follicle-stimulating hormone pretreatment for GnRH-induced fertility in patients with congenital hypogonadotropic hypogonadism. J Clin Endocrinol Metab.

57. Bouvattier C, Tauber Mn, Jouret B, Chaussain JL, Rochiccioli P. Gonadotropin treatment of hypogonadotropic hypogonadai adólescents. J Pediatr Endocrinol Metab. 1999;12(SUPPL. 1):339-344.

58. Zacharin M, Sabin MA, Nair V V., Dagabdhao P. Addition of recombinant follicle-stimulating hormone to human chorionic gonadotropin treatment in adolescents and young adults with hypogonadotropic hypogonadism promotes normal testicular growth and may promote early spermatogenesis. Fertil Steril. 2012;98(4):836-842. doi:10.1016/j.fertnstert.2012.06.022.

59. Albrecht A, Penger T, Marx M, Hirsch K, Dörr HG. Short-term adverse effects of testosterone used for priming in prepubertal boys before growth hormone stimulation test. $J$ Pediatr Endocrinol Metab. 2018;31(1):21-24. doi:10.1515/jpem-2017-0280.

60. Chatterjee R, Mukhopadhyay TN, Chandra S, Bajoria R. Sex steroid priming for induction of puberty in thalassemia patients with pulsatile reversible hypogonadotrophic hypogonadism. Hemoglobin. 2011;35(5-6):659-664. doi:10.3109/03630269.2011.630121.

61. Wehkalampi K, Widén E, Laine T, Palotie A, Dunkel L. Patterns of Inheritance of Constitutional Delay of Growth and Puberty in Families of Adolescent Girls and Boys Referred to Specialist Pediatric Care. J Clin Endocrinol Metab. 2008;93(3):723-728. doi:10.1210/jc.2007-1786.

62. Zhu J, Choa RE-Y, Guo MH, et al. A shared genetic basis for self-limited delayed puberty and idiopathic hypogonadotropic hypogonadism. J Clin Endocrinol Metab. 2015;100(4):E646-54. 
doi:10.1210/jc.2015-1080.

63. Cassatella D, Howard SR, Acierno JS, et al. Congenital hypogonadotropic hypogonadism and constitutional delay of growth and puberty have distinct genetic architectures. Eur J Endocrinol. 2018;178(4):377-388. doi:10.1530/EJE-17-0568.

64. Sedlmeyer IL, Palmert MR, Hospital CNS. Delayed puberty: Analysis of a large case series from an academic center. J Clin Endocrinol Metab. 2002;87(4):1613-1620. doi:10.1210/jcem.87.4.8395.

65. Dunkel L, Quinton R. Transition in endocrinology: Induction of puberty. Eur J Endocrinol. 2014;170(6). doi:10.1530/EJE-13-0894.

66. Neely EK, Hintz RL, Wilson DM, et al. Normal ranges for immunochemiluminometric gonadotropin assays. J Pediatr. 1995;127(1):40-46. doi:10.1016/S0022-3476(95)70254-7.

67. Boehm U, Bouloux P-M, Dattani MT, et al. Expert consensus document: European Consensus Statement on congenital hypogonadotropic hypogonadism--pathogenesis, diagnosis and treatment. Nat Rev Endocrinol. 2015;11(9):547-564. doi:10.1038/nrendo.2015.112. 


\section{Declaration of interest}

Authors declare that there is no conflict of interest that could be perceived as prejudicing the impartiality of the data reported.

Funding: The study was supported by funds from Italian Ministry of Health (Young Investigators funds: GR-2016-02362389) and IRCCS Istituto Auxologico Italiano (Ricerca Corrente funds: O5C202_2012).

\section{Author contributions statements:}

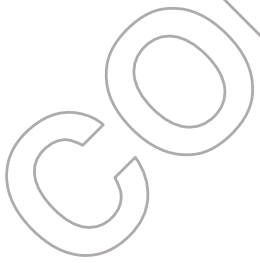

A.B. and B.C. conducted the literature review, A.B., B.C. and G.G. prepared the manuscript. S.F., V.V., P.D., L.G., E.G., M.B. and L.P. performed the critical revision of the manuscript. All authors read and approved the submitted version. 
Page 21 of 23

Figures

2

Figure 1. GnRH secretion profile in normal subjects, patients with constitutional delay of growth $4 \quad$ and puberty $(C D G P)$, and with partial and complete forms of congenital hypogonadotropic 5 hypogonadism (CHH). Adapted from Cangiano et al. 2020

6

7

8

9

10

11

12

13

14

15

16

17

18

19

20

21

22

23

24

25

26

27

28

29

30

31

32

33

34

35

36

37

38

39

40

41

42

43

44

45

46

47

48

49

50

51

52

53

54

55 


\section{Tables}

Table 1. pubertal delay classification

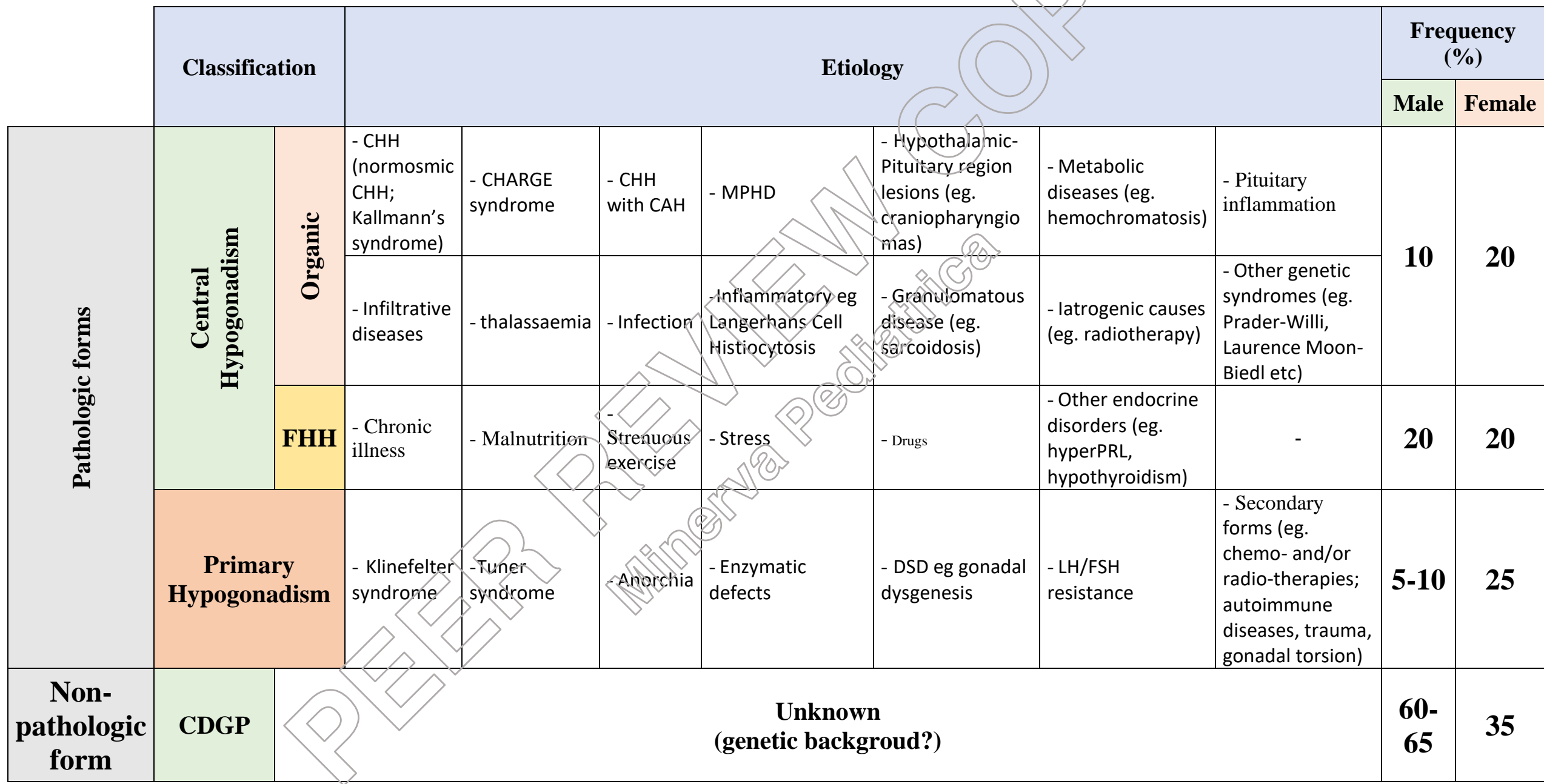


Page 23 of 23

1
2
3
3
4
5
5
6
7
7
8
9
10
10
11
12
13
13
14
15
16
16
17
18
18
19
20
21
21
22

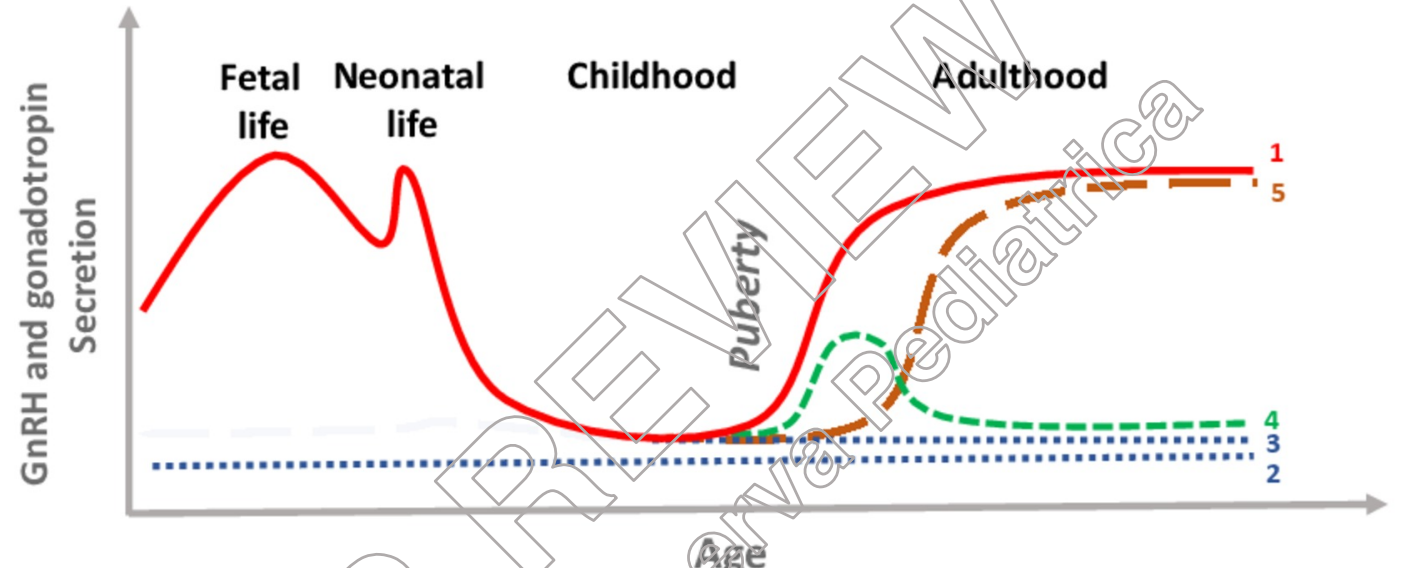

1: normal GnRH secretion profile

2 and 3: complete forms of CHH

4: partial forms of $\mathcal{C H} 4$

5: CDGP

Arge 